\title{
Investigation on functionalization of cotton and viscose fabrics with AgNWs
}

\author{
Patrycja Giesz • Ewelina Mackiewicz • Alicja Nejman • \\ Grzegorz Celichowski • Małgorzata Cieślak
}

Received: 8 August 2016/Accepted: 24 October 2016/Published online: 7 November 2016

(C) The Author(s) 2016. This article is published with open access at Springerlink.com

\begin{abstract}
A study on the functionalization of cotton and viscose fabrics to achieve bifunctional conductive and antibacterial properties was carried out; $0.5 \mathrm{wt} \%$ AgNW ethanolic colloid was prepared, and fabrics were dipped and dried in the colloid 1, 10 and 15 times. After one dipping, both fabrics remained nonconductive, and the surface resistance $\left(R_{\mathrm{s}}\right)$ of cotton was $4.9 \times 10^{10}$ and of viscose $3.6 \times 10^{11} \Omega$. Excellent conductivity properties were shown in cotton fabric after 10 dippings (20 $\Omega$ ) and in viscose fabric after 15 dippings (46 $\Omega$ ). The $\mathrm{Ag}$ content of these fabrics was 53.3 and $52.3 \%$ (SEM/EDX analysis) and 13.77 and $14.12 \%$ (TG/DTG analysis) for cotton and viscose, respectively. XRD analysis revealed the presence of AgNWs on the fabric surface. FTIR/ATR, Raman and TG analysis confirmed the effects of modifications. The AgNW layers on both fabric surfaces were resistant to abrasion. After 50 washes of the modified cotton fabric, $R_{\mathrm{S}}$ increased from 20 to $195 \Omega$. The AgNW layer was stable and the fabric still highly conductive. However, viscose fabric
\end{abstract}

P. Giesz · A. Nejman · M. Cieślak ( $\square)$

Textile Research Institute, Scientific Department of

Unconventional Technologies and Textiles, 5/15

Brzezińska St., 92-103 Lodz, Poland

e-mail: cieslakm@iw.lodz.pl

P. Giesz - E. Mackiewicz - G. Celichowski

Faculty of Chemistry, Department of Materials

Technology and Chemistry, University of Lodz, 163

Pomorska St., 90-236 Lodz, Poland became nonconductive after two washes, and the surface resistance increased from 46 to $1.4 \times 10^{11} \Omega$. The tensile strength of cotton modified with AgNWs increased by about $49 \%$ and for viscose decreased by about $27 \%$. AgNW-modified cotton fabric showed a significant antibacterial effect against $S$. aureus and $K$. pneumoniae bacteria. The presented method is more suitable for cotton because the modified cotton fabric retains the mechanical and conductive properties even after many washes.

Keywords Silver nanowires - Conductivity · Viscose $\cdot$ Cotton $\cdot$ Antibacterial

\section{Introduction}

The development of innovative textile materials aims to endow them with multifunctional properties (Foksowicz-Flaczyk et al. 2016). Several functions in one material are also expected in the area of textronic products called electronic textiles (E-textiles). Such products connect textiles and electronics and can be relevant for the development of smart materials capable of achieving a broad spectrum of functions, e.g., in flexible electronic products (Stoppa and Chiolerio 2014; Gowri et al. 2010). E-textile products have many applications, e.g., in biomedical sensors (electrocardiogram sensors), piezoresistive sensors, piezoelectric materials (optical resonator and 
transducer), rehabilitation (electromagnetic shields in physiotherapy) as well as professional sports and recreation (smart suits) (Rattfalt et al. 2007; Zhou et al. 2014; Capineri 2014; Usma et al. 2015; Dias 2015). Modifiers such as silver, carbon, gold and copper are the most common conductors and can be combined with various textile materials using conventional and unconventional methods (Cieślak et al. 2009; Stempien et al. 2016; Shateri-Khalilabad and Yazdanshenas 2013; Cui et al. 2015). In the last decade, much research has been dedicated to conductive textiles obtained by the application of carbon nanotubes (Kowalczyk et al. 2015; Nasirizadeh et al. 2015; Makowski et al. 2015), graphene, graphene oxide (Shateri-Khalilabad and Yazdanshenas 2013; Shen et al. 2016), carbon nanotubes and graphene oxide nanocomposites (Tang et al. 2014) or conductive polymers such as polypyrrole (Nateghi et al. 2013; Kim et al. 2013) and polyaniline (Zhao et al. 2013; Agarwal et al. 2016) and conductive polymers such as PEDOT/PSS (Tarabella et al. 2012). Silver has many excellent properties, including conductivity (Johnsen et al. 2012), good catalytic performance and antimicrobial activity (Jiang et al. 2005). The application of silver in the form of silver nanowires (AgNWs) is important in electronics as well as opto-electronic and nanoelectromechanic devices because of the unique properties, which are not seen in three-dimensional materials (Nateghi and Shateri-Khalilabad 2015). The application of AgNWs to modify textile substrates enables obtaining multifunctional products. Additionally, the combination of AgNWs, e.g., with photocatalysts, gives new opportunities to obtain functional materials with high potential for applications (Eom et al. 2014; Dong et al. 2014). With the development of wearable devices and electronic textiles, there will be increasing development of electrically conducting pathways produced using conventional fiber and yarn substrates. The methods of deposition, spinning, printing, coating, dipping and solution growing to obtain conductive materials have been widely used (Cui et al. 2015).

The aim of this article was to develop electroconductive and antibacterial cotton (natural fibers) and viscose (chemical fibers) fabrics by modification with an AgNW colloid. The obtained modification effect, impact of AgNW application on fabrics' tensile strength and durability of AgNW layers on fabric surfaces were assessed.

\section{Materials and methods}

Preparation of AgNW colloids

AgNWs were synthesized by a polyol process in which silver nitrate $\left(\mathrm{AgNO}_{3}\right.$, Aldrich) was reduced with ethylene glycol (EG, POCH) in the presence of polyvinylpyrrolidone (PVP, Aldrich). PVP is an amorphous polymer, which is highly soluble in polar solvents, that directs the growth of nanowires and protects them from agglomeration (Xia and Sun 2002; Mohd et al. 2014; Shobin and Manivannan 2014; Sun et al. 2002). Briefly, $10 \mathrm{ml}$ of $0.45 \mathrm{M}$ EG solution of PVP $\left(M_{\mathrm{w}}=55000\right)$ with $7 \mathrm{mg}$ of sodium chloride $(\mathrm{NaCl}, \mathrm{CHEMPUR})$ was prepared and heated to $170{ }^{\circ} \mathrm{C}$. Chloride ions were added as the mediating agent to facilitate the growth of AgNWs. Then, $5 \mathrm{ml}$ of $0.12 \mathrm{MEG}$ solution of $\mathrm{AgNO}_{3}$ was injected at a rate of $5 \mathrm{ml} / \mathrm{h}$. During the synthesis, the solution was magnetically stirred. When the silver precursor solution was added, the colloid was heated for $60 \mathrm{~min}$ at $170{ }^{\circ} \mathrm{C}$ and finally air-cooled to about $22{ }^{\circ} \mathrm{C}$. To remove EG and excess PVP from the colloid, the solution was diluted with acetone ( $\mathrm{POCH}$ ) (at a 1:10 ratio) and centrifuged for $10 \mathrm{~min}$. Finally, the nanowires were dispersed in ethanol (POCH) to form the $0.5 \mathrm{wt} \%$ alcoholic colloid.

Deposition of AgNW colloid on fabric surfaces

The samples of $100 \%$ cotton $\left(108 \mathrm{~g} / \mathrm{m}^{2}\right.$, pick and end densities-warp 43 and weft 32 ) and $100 \%$ viscose $\left(104 \mathrm{~g} / \mathrm{m}^{2}\right.$, pick and end densities-warp 32 and weft 25) plain woven fabrics were dipped in the $\mathrm{AgNW}$ colloid for $1 \mathrm{~min}$, and then the fabrics were dried at room temperature for $30 \mathrm{~min}$ (dipping and drying method). This method was used 1 and 10 times (for cotton fabric) and 1, 10 and 15 times (for viscose fabric) to vary the AgNW content on the fabrics. The AgNW content on cotton after 1 dipping was $1 \mathrm{~g} / \mathrm{m}^{2}$ and after 10 dippings $9 \mathrm{~g} / \mathrm{m}^{2}$; for viscose after 1 dipping it was $0.9 \mathrm{~g} / \mathrm{m}^{2}$, after 10 dippings $6.2 \mathrm{~g} / \mathrm{m}^{2}$ and after 15 dippings $8.4 \mathrm{~g} / \mathrm{m}^{2}$.

Methods

The optical absorbance spectra of AgNW colloids were obtained using an Ocean Optics USB2000+ spectrophotometer and ethanol as the reference. 
Microscopic analysis of AgNWs deposited on the carbon-coated copper grids was performed using a scanning transmission electron microscope (STEM) (Nova NanoSEM 450 FEI, USA). Microscopic analyses of unmodified cotton fabric (CO) and viscose fabric (CV) and AgNW-modified fabrics were carried out with a scanning electron microscope (SEM) (Nova NanoSEM 450 FEI, USA, and Vega 3 Tescan, Czech Republic). The elemental composition analysis was made with an X-ray microanalyzer (INCA Energy EDX, Oxford Instruments Analytical, UK) connected to a Vega 3 SEM. Alicona MeX software for 3D SEM images of modified fabrics was used. On the basis of the 3D SEM analysis, the values of the average height of the selected area $\left(S_{\mathrm{a}}\right)$, root-mean-square height of the selected area $\left(S_{\mathrm{q}}\right)$ and maximum height of the selected area $\left(S_{\mathrm{z}}\right)$ were determined. Surface resistance $\left(R_{\mathrm{s}}\right)$ of unmodified and $\mathrm{AgNW}$-modified fabrics was evaluated according to standard PN-P-04871:1991. The measurements were carried out with a set of standardized measurement electrodes, a digital DM53 multimeter (Polmed(+), Poland) and 6206 teraohmmeter (ELTEX, Germany). The fabrics were tested in an air-conditioned HCZ $0030 \mathrm{~L}(\mathrm{M})$ chamber (Heraeus, Germany) at a temperature of $23 \pm 1{ }^{\circ} \mathrm{C}$ and relative humidity of $25 \pm 5 \%$. Before testing, samples were conditioned under the same conditions for $24 \mathrm{~h}$. FTIR/ATR spectra of unmodified and modified fabrics and PVP powder were recorded with $4 \mathrm{~cm}^{-1}$ resolution over the range $600-4400 \mathrm{~cm}^{-1}$ using a Vertex 70 FTIR spectrometer (Bruker, Germany). Raman spectra of the AgNW colloid (after drying) and fabrics were obtained with a Raman Renishaw InVia Reflex with a Leica microscope (Renishaw, GB), and a nearinfrared semiconductor laser $(\lambda=785 \mathrm{~nm})$ was used as an excitation source. The laser beam was focused on the samples by a $50 \times$ objective lens. Laser power and scanning times were determined experimentally. The signal was recorded by a CCD detector. Spectra were baseline corrected using WIRE 3.2. software. The $\mathrm{X}$-ray diffraction technique (XRD) on an Empyrean diffractometer (PANalytical), working in grazing incidence (GIXRD) with Co kA (1.78901 A) mode radiation to measure the AgNW colloid and fabrics, was used. The incidence angle (omega) was set to $2^{\circ}$. The thermogravimetric analysis of the PVP powder, AgNW colloid (after drying) and fabrics was carried out using a TG 209F1 Libra analyzer (Netzsch, Germany) with a heating rate of $10{ }^{\circ} \mathrm{C} \mathrm{min}^{-1}$ under a nitrogen flow rate of $20 \mathrm{ml} \mathrm{min}{ }^{-1}$ over the range of 30-800 ${ }^{\circ} \mathrm{C}$. The fabric samples at about $6 \mathrm{mg}$ and the dry residue of the $\mathrm{AgNW}$ colloid at about $2 \mathrm{mg}$ were tested in a ceramic crucible. Further data processing was done using the ICDD PDF 4 database and HighScore Plus software. The washing durability of AgNW-modified fabrics was evaluated according to standard PN EN ISO 6330:2012. The Ag percentage weight in AgNW-modified fabrics before and after washing was evaluated on the basis maps collected from $100 \mu \mathrm{m} \times 100 \mu \mathrm{m}$ surfaces using the SEM/ EDX technique. As a complementary technique, TG/ DTG analysis was used. The abrasion resistance of AgNWs on both fabric surfaces using Stainingtester (Hungary) was examined. A pin diameter of $10 \mathrm{~mm}$ and press force of $9 \mathrm{~Pa}$ were used. Twenty abrasion cycles were carried out. Tensile strength tests before and after fabric modification were performed according to standard PN-EN ISO 13934-1:2013-07 using an Instron 3367 Tensile Test Machine (UK). The breaking force and breaking elongation values were determined. The antibacterial activity of AgNWmodified $\mathrm{CO}$ fabric was studied according to the AATCC 100-2004 and PN-EN ISO 20743 standards using Staphylococcus aureus (S. aureus, ATCC 6538, gram-positive bacterium) and Klebsiella pneumoniae (K. pneumoniae, ATCC 4352, gram-negative bacterium) as model microorganisms. Approximately $0.6 \times 10^{5}$ and $1.8 \times 10^{5}$ per $\mathrm{ml}(\mathrm{CFU} / \mathrm{ml})$ colonyforming $S$. aureus and $K$. pneumoniae were inoculated, respectively. Inhibition zones were measured after $21 \mathrm{~h}+48 \mathrm{~h}$ of incubation at $37 \pm 2{ }^{\circ} \mathrm{C}$.

\section{Results and discussion}

AgNW colloid

For characterization of the AgNW colloid used in the modification of fabrics, UV-Vis spectroscopy and microscopy analyses were used. Figure 1 shows the absorption spectrum taken from the as-prepared AgNW colloid. The appearance of a peak at $350 \mathrm{~nm}$ can be attributed to the plasmon response of the long silver nanowires similar to that of the bulk silver. The absorption peak at around $380 \mathrm{~nm}$ can be considered the transverse mode of AgNWs (Sun et al. 2002; Wang et al. 2005).

STEM images of synthesized AgNWs at different magnifications are shown in Fig. 2. The silver 


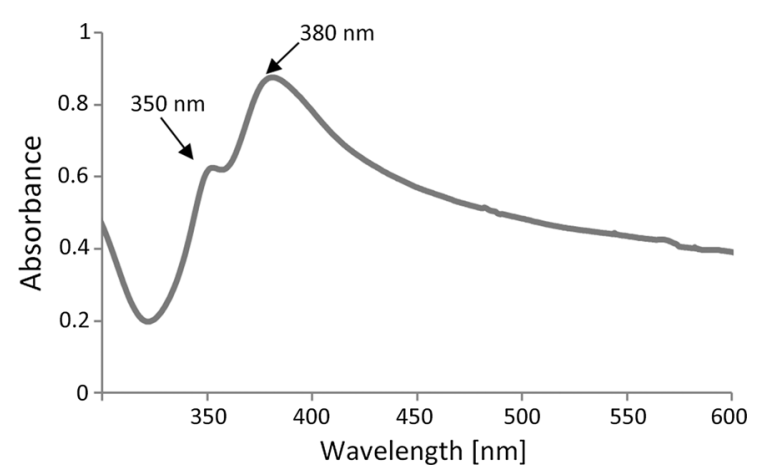

Fig. 1 UV-Vis spectrum of AgNW colloid

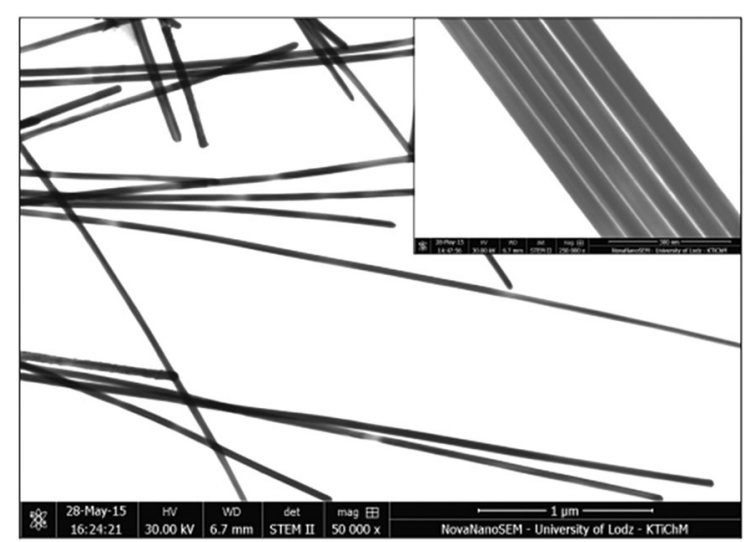

Fig. 2 STEM image of AgNWs with $\times 50,000$ and $\times 250,000$ magnifications

nanowires (AgNWs) are homogeneous in morphology and not agglomerated. The nanowire diameters were $46 \pm 2 \mathrm{~nm}$.

\section{Conductivity}

AgNW-modified cotton and viscose fabrics change color from white to silver gray, which is consistent with literature reports (Cui et al. 2015; Nateghi and

Table 1 Surface resistance $\left(R_{\mathrm{s}}\right)$ of unmodified and AgNWmodified $\mathrm{CO}$ and $\mathrm{CV}$

\begin{tabular}{lll}
\hline $\begin{array}{l}\text { Number of fabric dippings } \\
\text { in AgNW colloid }\end{array}$ & $\mathrm{CO}$ & $\mathrm{CV}$ \\
\hline $\begin{array}{l}\text { Surface resistance, } R_{\mathrm{S}}(\Omega) \\
0\end{array}$ & $2.4 \times 10^{12}$ & $8.9 \times 10^{11}$ \\
1 & $4.9 \times 10^{10}$ & $3.6 \times 10^{11}$ \\
10 & 20 & $8.6 \times 10^{4}$ \\
15 & - & 46 \\
\hline
\end{tabular}

Fig. $3 \mathrm{SEM} / \mathrm{EDX}$ analysis of a CO, b CO1AgNW and c CO10AgNW fabrics

Shateri-Khalilabad 2015). The unmodified CO and $\mathrm{CV}$ fabrics are nonconductive, and their surface resistance amounted to $2.4 \times 10^{12}$ and $8.9 \times 10^{11}$, respectively (Table 1). After one dipping in the AgNW colloid, a few AgNWs were observed on $\mathrm{CO} 1 \mathrm{AgNW}$ and CV1AgNW fabrics. The percentage weight of $\mathrm{Ag}$ on the basis of SEM/EDS analysis amounted to $3.8 \%$ (CO1AgNWs) and $1.4 \%$ (CV1AgNWs) (Figs. 3b, 4b), and the surface resistance $\left(R_{\mathrm{S}}\right)$ decreased for CO1AgNWs by about two orders of magnitude and was not changed for CV1AgNWs (Table 1). After ten dippings of the CO fabric in the AgNW colloid, the Ag content was $53.3 \%$; the fabric became conductive, and the $R_{\mathrm{S}}$ value was $20 \Omega$ (Fig. 3c; Table 1). For the CV fabric after ten dippings, the Ag content was $34.8 \%$, and $R_{\mathrm{s}}$ was $8.6 \times 10^{4} \Omega$ (Fig. $4 \mathrm{c}$; Table 1). The CV10AgNW fabric was also conductive, but the effect was worse compared to $\mathrm{CO}$ fabric. The electrical properties depend on electrically conductive paths formed by AgNWs. The increase in the amounts of AgNWs causes better interconnection between silver nanowires, which allows for good electrical conductivity. After 15 dippings, the $\mathrm{CV}$ fabric achieved high conductivity, and the $R_{\mathrm{s}}$ amounted to $46 \Omega$ (Ag content $52.3 \mathrm{wt} \%$ ) (Fig. 4d; Table 1). In the same conditions, more effective AgNW modification of $\mathrm{CO}$ compared to the CV surface was observed. For further studies, we selected the best electrically conductive textiles: $\mathrm{CO}$ fabric after 10 dippings in AgNWs (CO10AgNWs) (Fig. 3c) and CV fabric after 15 dippings (CV15AgNWs) (Fig. 4d). The surface resistance of PET/CO woven fabric modified with carbon nanotubes was in the range of $5.79 \times 10^{3}-$ $1.03 \times 10^{3} \Omega$, respectively, from one to four paddings with nanotubes (Kowalczyk et al. 2015). Cui et al. (2015) examined the influence of the strain of cupro fabrics modified with AgNWs on electrical conductivity; low resistance and good stretchability in the range of $4.7-9.1 \times 10^{-3} \Omega$ in the strain range of 0-190\% were obtained. Shen et al. (2016) obtained electrical cotton fabric dyeing with reduced graphene oxide. The lowest surface resistance was $1.43 \times 10^{3} \Omega / \mathrm{cm}$ at the seventh dyeing cycle. 
(a)
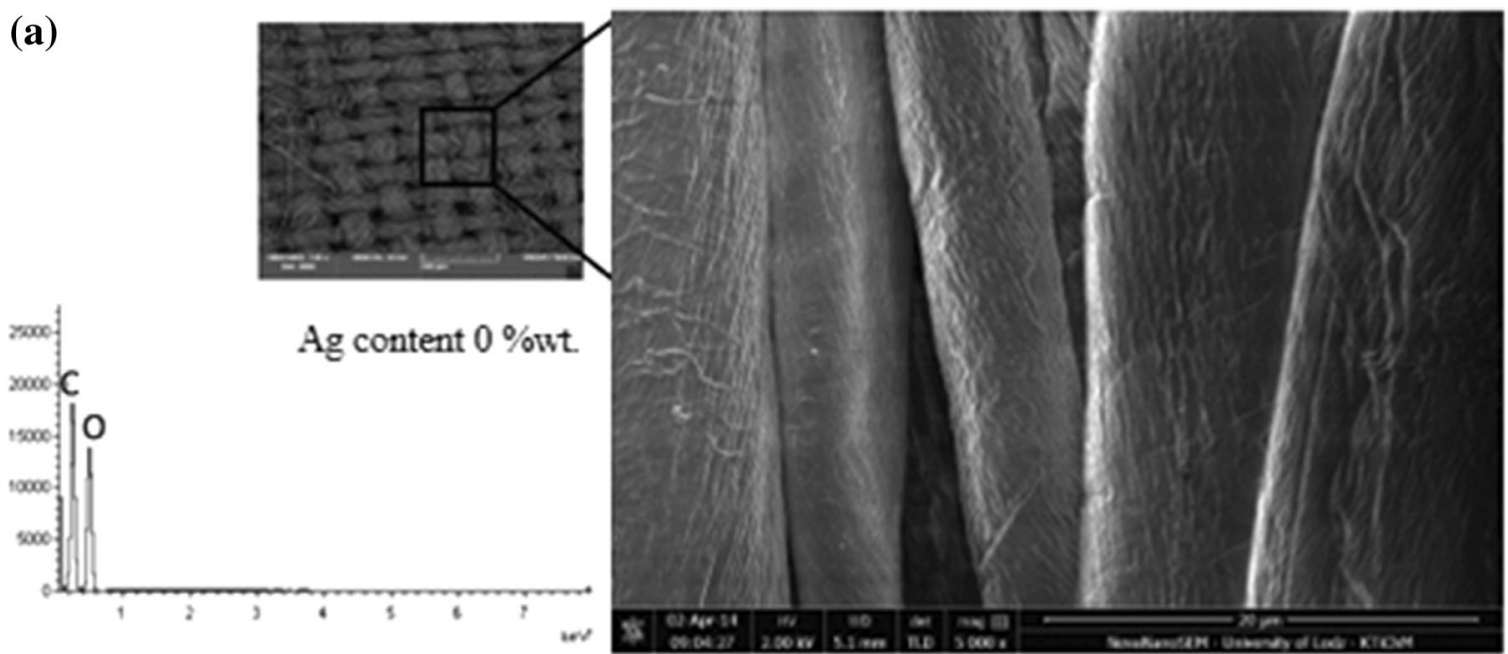

(b)
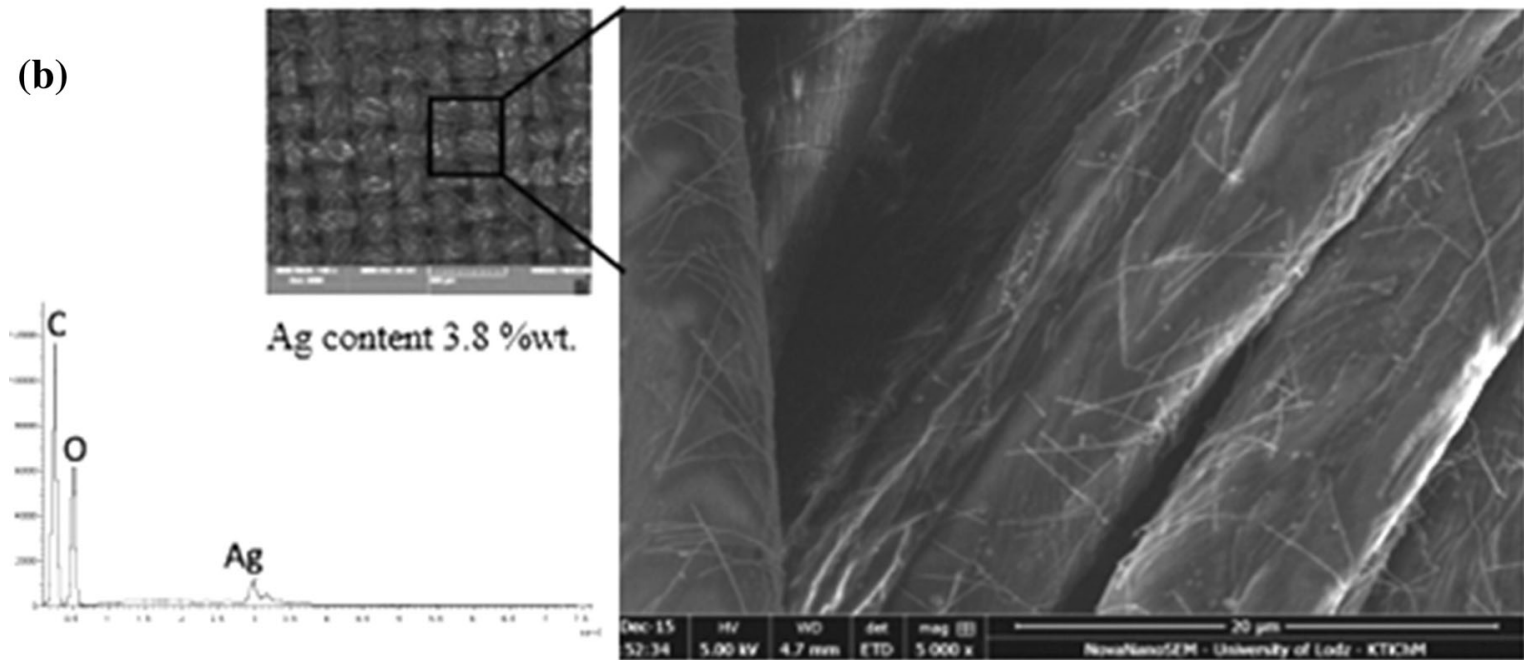

(c)
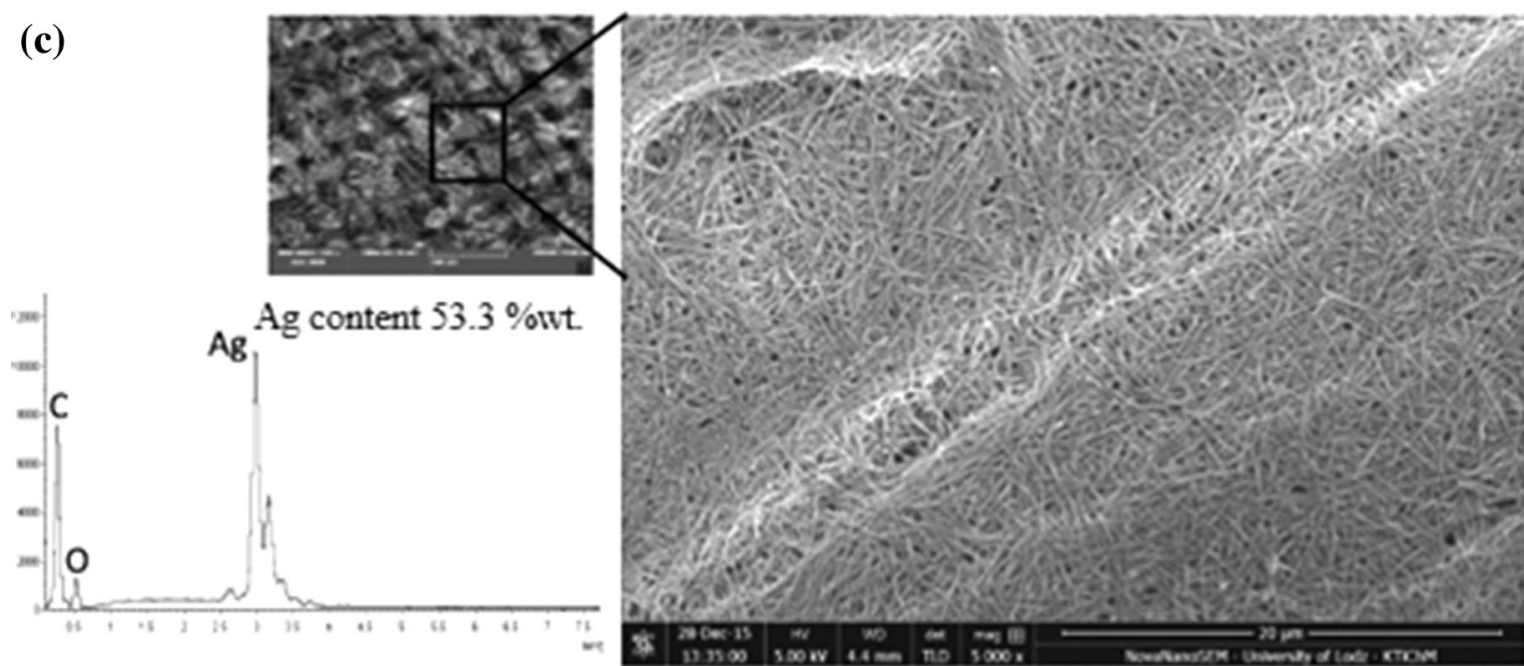
Fig. 4 SEM/EDX analysis of a CV, b CV1AgNW, c CV10AgNW and d CV15AgNW fabrics

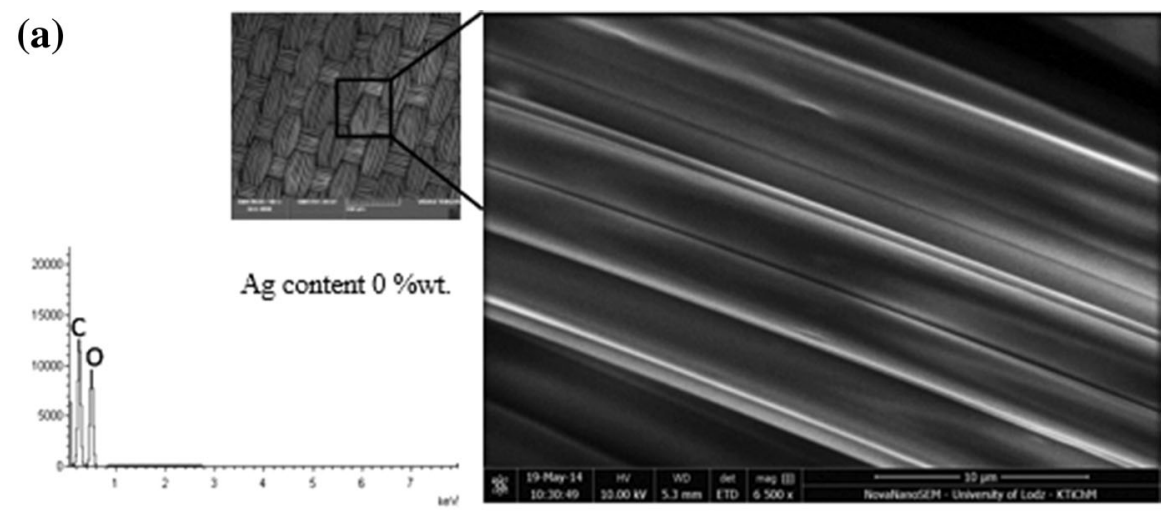

(b)
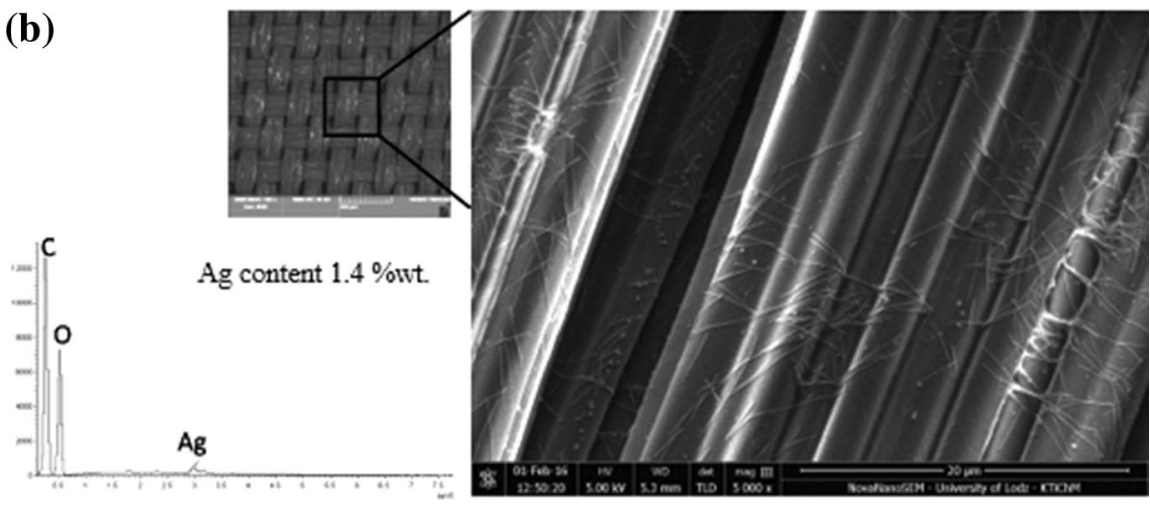

(c)
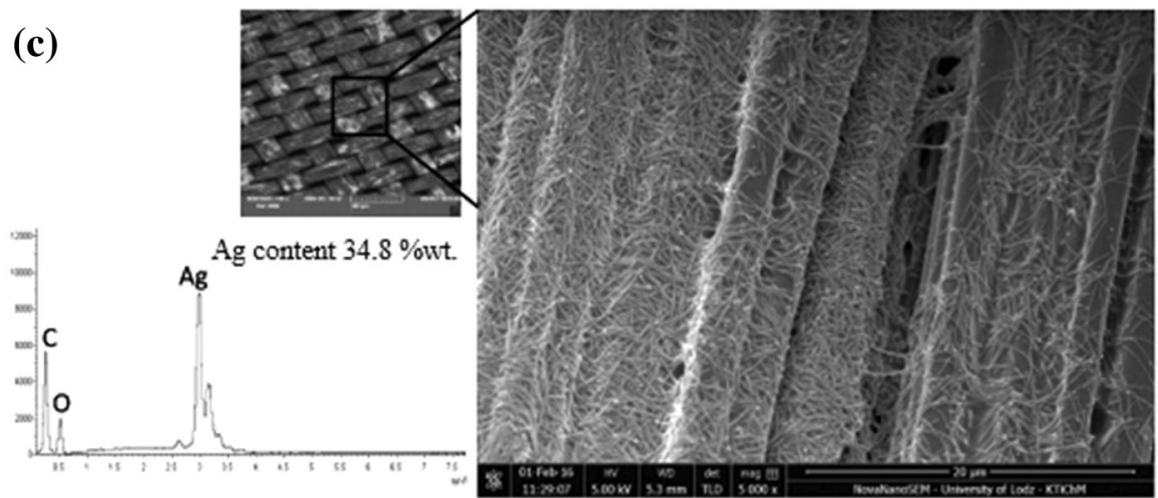

(d)
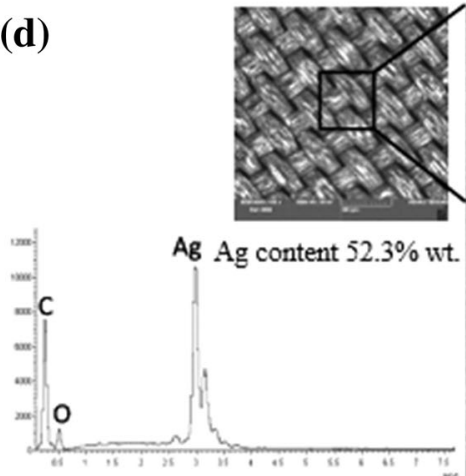
Tarabella et al. (2012) prepared conductive cotton fiber modified with functionalized poly(3,4-ethylenedioxythiophene) doped with poly(styrene sulfonate) (PEDOT:PSS) with electrical resistance of $4.3 \times 10^{2} \Omega / \mathrm{cm}$.

Surface analysis

The 3D SEM pictures (Fig. 5) show the changes in the surface topography of fibers after AgNW deposition. To evaluate the changes in surface roughness of AgNW-modified fabrics, 3D SEM pictures were made. The $3 \mathrm{D}$ pictures of unmodified $\mathrm{CO}$ and $\mathrm{CV}$ fabric surfaces and the roughness parameters were shown by Giesz et al. (2016). Obtained by this research team, the value of the root-mean-square height in the selected area $\left(S_{\mathrm{q}}\right)$ for unmodified $\mathrm{CO}$ and CV was 44 and $9 \mathrm{~nm}$, respectively. The roughness of fabric surfaces after AgNW deposition was determined. The value of $S_{\mathrm{q}}$ for the measured area of $64 \mu^{2}$ was 197 and $216 \mathrm{~nm}$ for CO10AgNWs and CV15AgNWs, respectively. Other measured roughness parameters such as the average height $S_{\text {a }}$ increased from $33 \mathrm{~nm}$ (CO) to $155 \mathrm{~nm}$ (COAgNWs10) and from $7 \mathrm{~nm}(\mathrm{CV})$ to $171 \mathrm{~nm}$

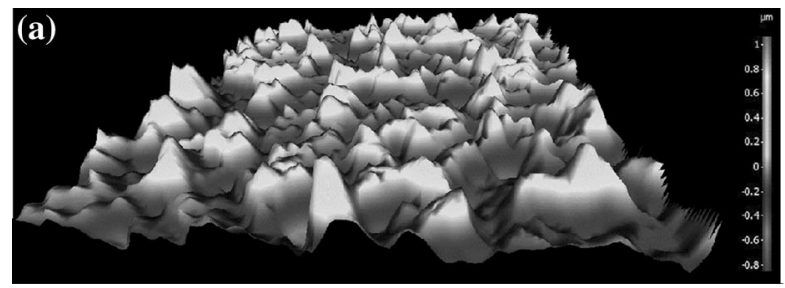

(CV15AgNWs). The increase of maximum height $S_{\mathrm{z}}$ before and after modification was also observed from $547 \mathrm{~nm}(\mathrm{CO})$ to $1.84 \mu \mathrm{m}$ for CO10AgNWs and from $124 \mathrm{~nm}(\mathrm{CV})$ to $1.88 \mu \mathrm{m}$ for $\mathrm{CV} 15 \mathrm{Ag}$ NWs.

Vibrational spectroscopy techniques were used for the assessment of AgNW layers directly on the fabric surface. On the FTIR/ATR spectrum of PVP powder (Figs. 6, 7a), the band at $3419 \mathrm{~cm}^{-1}$ and four peaks with the maximum at $2952 \mathrm{~cm}^{-1}$ corresponded to $-\mathrm{OH}$ stretching and $\mathrm{C}-\mathrm{H}$ stretching vibrations, respectively. The peak at $1647 \mathrm{~cm}^{-1}$ corresponded to the stretching vibrations of $\mathrm{C}=\mathrm{O}$ in the $\mathrm{PVP}$. Other peaks at 1281 and $1425 \mathrm{~cm}^{-1}$ referred to the $\mathrm{C}-\mathrm{N}$ stretching vibration and the $\mathrm{CH}_{2}$ groups in the pyrrole ring of PVP (Selvam and Sundrarajan 2012). On the FTIR/ ATR spectrum of CO10AgNW fabric, the broad band peak corresponding to $-\mathrm{OH}$ stretching shifted to a lower wave number from $3332 \mathrm{~cm}^{-1}$ (Fig. 6a, CO fabric) to $3286 \mathrm{~cm}^{-1}$ (Fig. 6b, CO10AgNW fabric). Also in the CV15AgNW fabric spectrum, the $-\mathrm{OH}$ stretching band shifted from $3333 \mathrm{~cm}^{-1}$ (Fig. 7a, CV fabric) to $3324 \mathrm{~cm}^{-1}$ (Fig. 7b, CV15AgNW fabric). The $\mathrm{C}=\mathrm{O}$ stretching band of CO10AgNW fabric shifted from 1641 to $1648 \mathrm{~cm}^{-1}$ (Fig. 6a, b) and for

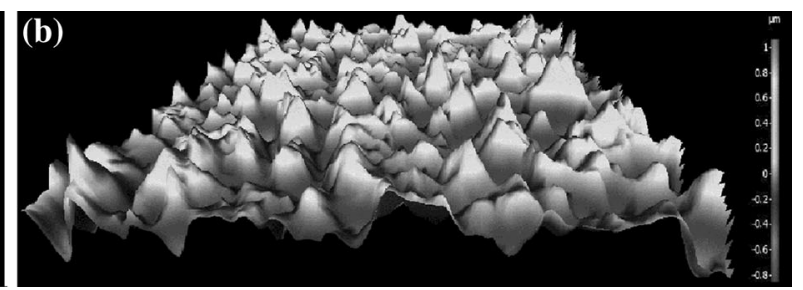

Fig. 5 Three-dimensional SEM pictures of a CO10AgNW and b CV15AgNW fabrics

Fig. 6 FTIR analysis of a CO fabric, b CO10AgNW fabric and $\mathbf{c}$ PVP powder

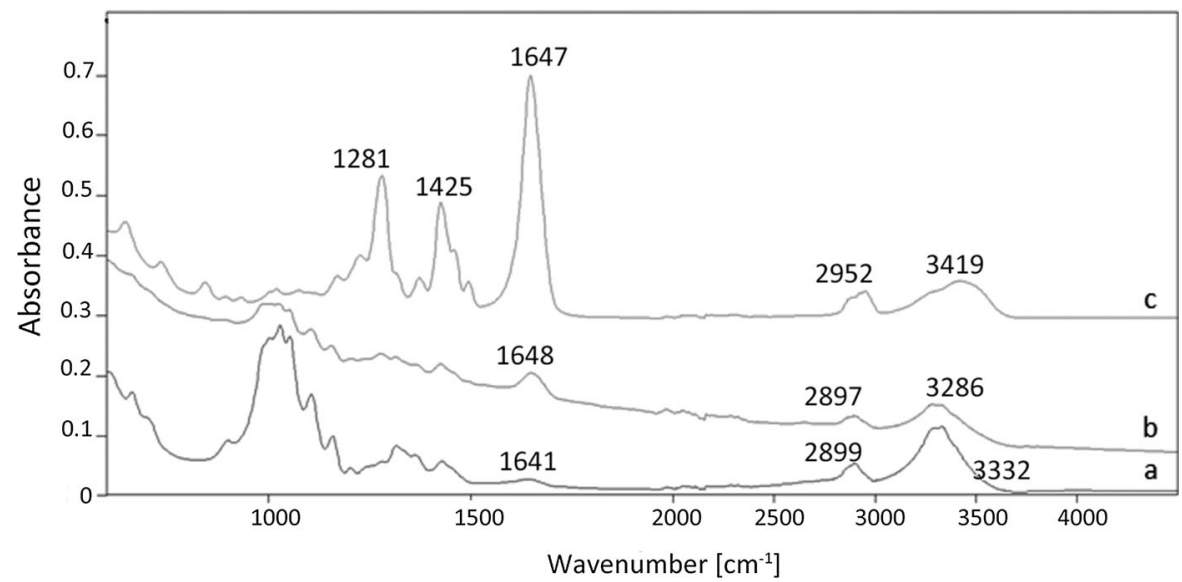


Fig. 7 FTIR analysis of a CV fabric, b CV15AgNW fabric and c PVP powder

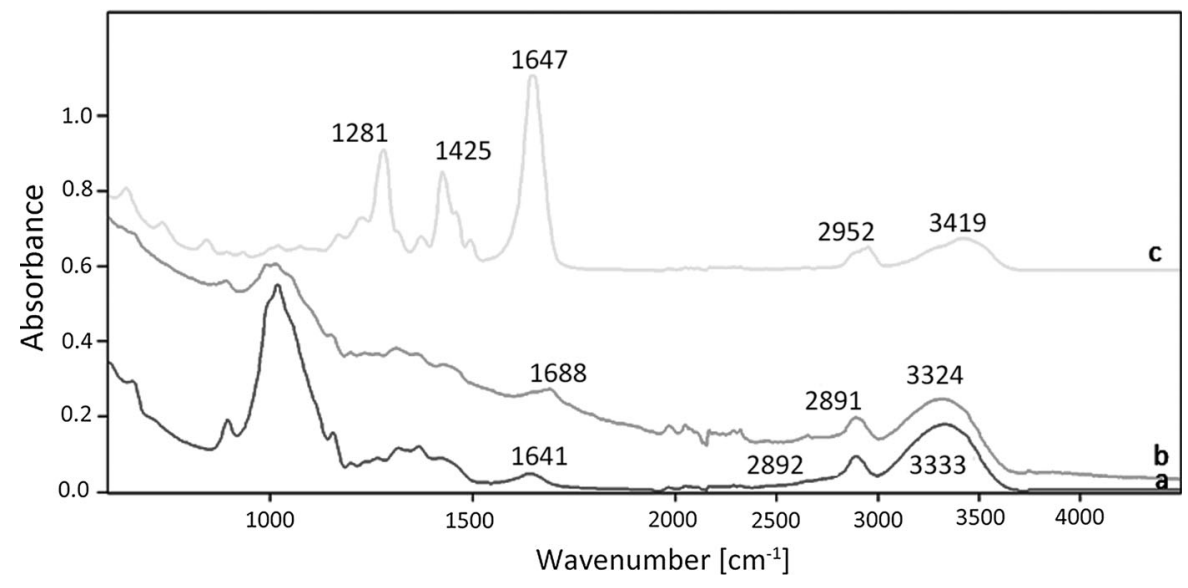

CV15AgNW fabric shifted strongly from 1641 to $1688 \mathrm{~cm}^{-1}$ (Fig. 7a, b). These changes were evidence of the interaction among cellulose, PVP and silver nanowires. Sundarshan Reddy et al. (2012) examined hydroxypropyl cellulose (HPC) and PVP in aqueous solutions. On the basis of FTIR analysis, they found the formation of strong hydrogen bonds between HPC ( $-\mathrm{OH}$ group) and PVP ( $\mathrm{C}=\mathrm{O}$ group) by the shift of absorption bands. Also, interaction between PVP and cotton was observed by Selvam and Sundrarajan (2012). Additionally, Hong et al. (2010) observed broadened and shifted $\mathrm{C}=\mathrm{O}$ stretching bands of the silver/PVP nanocpomosite compared to the PVP powder band. This was associated with the formation of a coordination bond between the silver and oxygen atoms in the $\mathrm{C}=\mathrm{O}$ group.

Raman analysis confirmed the FTIR/ATR analysis and additionally as a complementary technique showed a strong band at $239 \mathrm{~cm}^{-1}$ (Fig. 8c). As reported by Wang et al. (1999) and Martina et al. (2012), this vibration was characteristic for the Ag-O mode, silver's interaction with oxygen molecules. Bands from PVP at $746 \mathrm{~cm}^{-1}$ (C-N stretching vibrations), 938, $938 \mathrm{~cm}^{-1}$ (C-C stretching vibrations) (Fig. 8d) and 748, $937 \mathrm{~cm}^{-1}$ (Fig. 9d) in CO10AgNW and CV15AgNW fabrics, respectively, were noticed. The band at $1687 \mathrm{~cm}^{-1}$ for CV15AgNW fabric (Fig. 9d) was attributed to $\mathrm{C}=\mathrm{O}$ stretching vibrations from PVP, and it was not observed for CO10AgNW fabric (Fig. 8d). On the Raman spectrum of CO10AgNW and CV15AgNW fabrics, bands at 1235 and $1428 \mathrm{~cm}^{-1}$ corresponded to $\mathrm{C}-\mathrm{N}$ stretching and $\mathrm{C}-\mathrm{H}$ bending vibrations of PVP, respectively (Bahadur et al. 2016). The presence of the above bands from PVP in the AgNW colloid spectrum was also observed (Figs. 8c, 9c).

The XRD results of CO10AgNW, CV15AgNW fabrics and AgNW colloid confirmed the presence of metallic silver on the fabric surface and in colloidal solution. The two diffraction peaks centered at two theta around at $44.59^{\circ}(200)$ and $51.93^{\circ}(002)$ are characteristic for silver. Other reflections at $26.87^{\circ}$, $40.80^{\circ}$ and $22.57^{\circ}, 25.54^{\circ}$ corresponded to the crystal structure of $\mathrm{CO}$ and $\mathrm{CV}$, respectively (Fig. 10).

The Ag percentage weight on the surface in relation to other percentage weights of elements in the fabrics before and after washing was evaluated by the energydispersive X-ray spectroscopy technique. The Ag content before washing was 53.5 and $52.3 \%$ for CO10AgNW and CV15AgNW fabric, and the surface resistance was 20 and $46 \Omega$, respectively. After 25 washes (CO10AgNWs/25), the Ag content decreased by about $9 \mathrm{wt} \%$, but the fabric still exhibited high conductivity; the surface resistance $\left(R_{\mathrm{S}}\right)$ was $55 \Omega$ (Fig. 11; Table 2). After 50 washes (CO10AgNWs/ 50 ), the Ag content decreased about $11 \mathrm{wt} \%$, and $R_{\mathrm{S}}$ was $195 \Omega$. It was found that after the first 25 washes, the Ag content decreased the most, while after the next 25 washes, it decreased slightly. For CV15AgNWs after the first (CV15AgNWs/1) and second washes (CV15AgNWs/2), the Ag content decreased from 52.3 to $13.3 \mathrm{wt} \%$ and $3.9 \mathrm{wt} \%$, respectively. Therefore, the conductivity decreased, and after the second wash the CV15AgNWs/2 fabric was nonconductive. The loss of AgNWs as the result of washing was shown by SEM/ EDS analysis (Fig. 11).

In the SEM/EDX technique, only the surface is analyzed because thermogravimetric analysis as a 

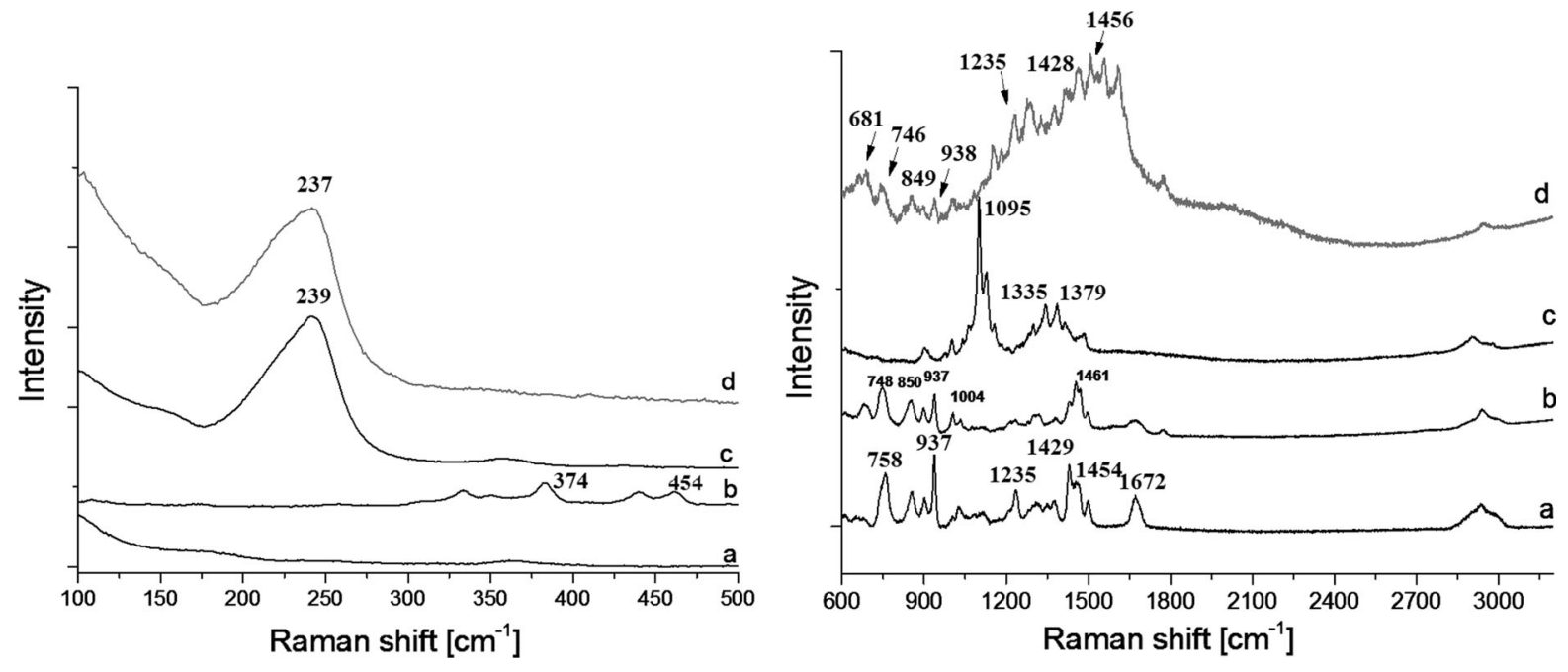

Fig. 8 Raman analysis of a PVP powder, b AgNW colloid, c CO fabric and d CO10AgNW fabric

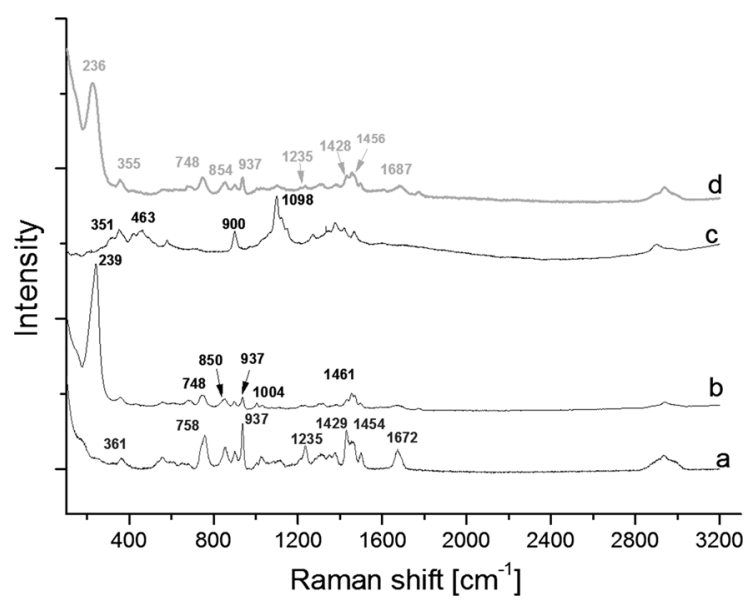

Fig. 9 Raman analysis of a PVP powder, b AgNW colloid, c CV fabric and d CV15AgNW fabric

complementary technique is used. This technique allows for evaluation of the Ag percentage weight over the entire volume of the fabric.

Thermogravimetric analysis

On the basis of the thermogravimetric (TG) analysis, it was noticed that the thermal decomposition of the AgNW colloid started at $392.4{ }^{\circ} \mathrm{C}$ with the maximum peak at $430.6{ }^{\circ} \mathrm{C}$. This peak is assigned to polyvinylpyrrolidone (PVP), surrounding and stabilizing the AgNW in colloid. The pattern of PVP powder was also examined, and the thermal decomposition occurred at $414.3{ }^{\circ} \mathrm{C}$ with the maximum peak at $434.0{ }^{\circ} \mathrm{C}$ (Table 3; Fig. 12). Based on the weight loss value of PVP and AgNW colloid, the amount of AgNWs in the colloid was $37.84 \%$. The concentration of silver nanowires in ink was studied by Tao et al. (2013). They prepared ink with $15 \%$ solid content. Based on TG/DTG analysis, they confirmed that the ink contained $15.2 \%$ silver nanowires.

The peaks near $414{ }^{\circ} \mathrm{C}(\mathrm{CO} 10 \mathrm{AgNWs})$ and $385^{\circ} \mathrm{C}$ (CV15AgNWs) came from PVP (Table 3; Fig. 13). The amounts of AgNWs for CO1AgNW and CO10AgNW fabric were 1.15 and $13.77 \%$, respectively (Table 3; Fig. 10). For CO10AgNW fabric after 25 and 50 washes, the amount of AgNWs decreased slighty to $10.62 \%(\mathrm{CO} 10 \mathrm{AgNWs} / 25)$ and $10.75 \%$ (CO10AgNWs/50), respectively (Table 3). The amounts of AgNWs after 1, 10 and 15 dippings of the CV fabric were 1.89, 9.97 and $14.12 \%$, respectively (Table 3; Fig. 13). After the first (CV15AgNWs/1) and second (CV15AgNWs/2) washes of CV15AgNW fabric, the amount of AgNWs decreased from 14.12 to $5.71 \%$ and $4.47 \%$, respectively (Table 3). It was observed that the effect of AgNW modification of the CV fabric was not resistant to washing as opposed to $\mathrm{CO}$ fabric.

The Ag content of modified fabrics obtained from SEM/EDS and TG analysis is different because of various measurement techniques. As mentioned at the beginning, the sample in TG analysis is measured over the entire volume, while in SEM/EDS analysis only the surface is analyzed. However, despite these differences, the relationship of the $\mathrm{Ag}$ content 
Fig. 10 XRD analysis of a AgNW colloid, $b$ CO10AgNW and $c$ CV15AgNW fabrics
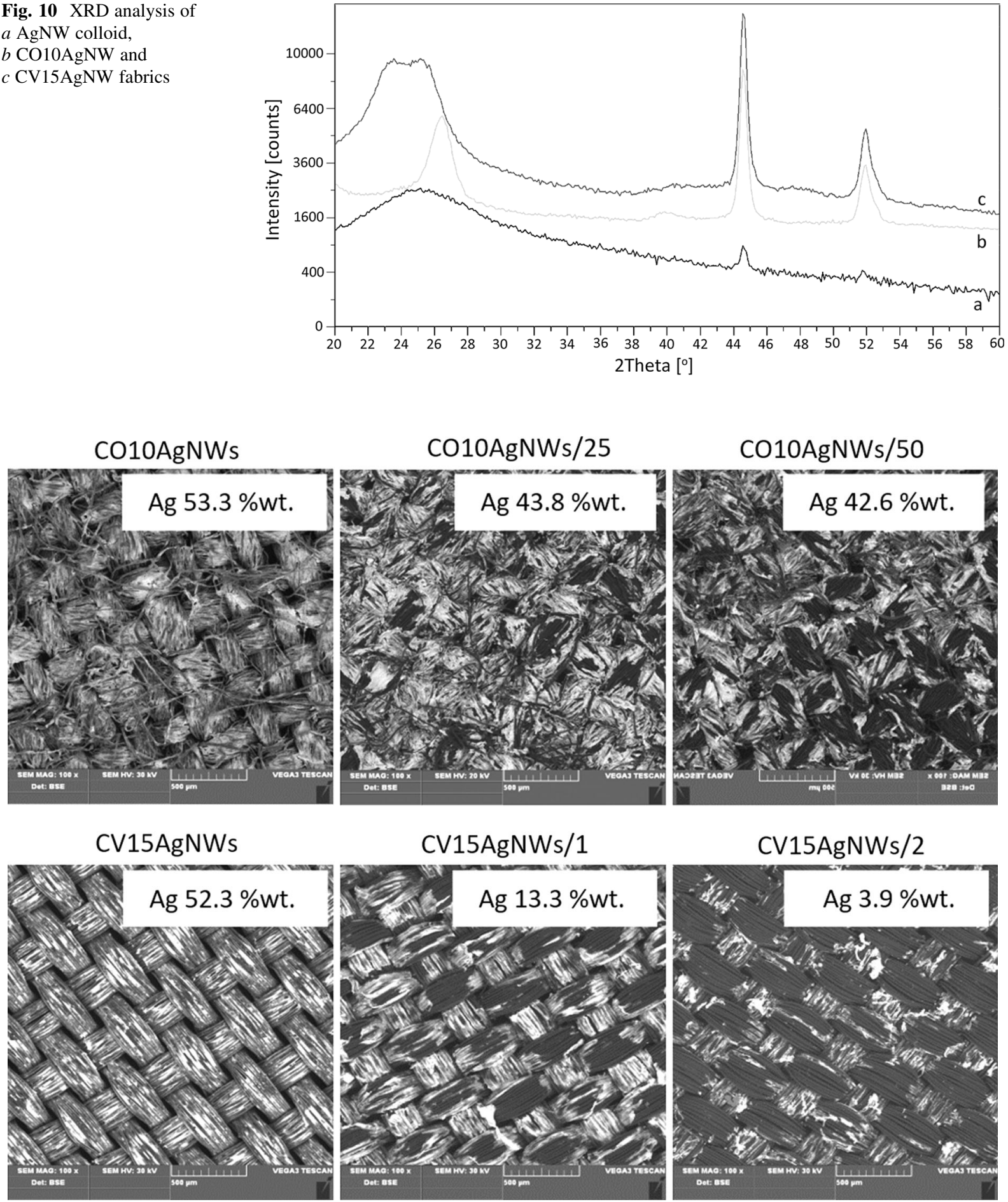

Fig. $11 \mathrm{SEM} / \mathrm{EDX}$ analysis of AgNW-modified CO and CV fabrics before and after 25 and 50 washes (CO10AgNWs/25 and CO10AgNWs/50) and 1 and 2 washes (CV15AgNWs/1 and CV15AgNWs/2) 
Table 2 Surface resistance of CO10AgNW and CV15AgNW fabric before and after washing

\begin{tabular}{lll}
\hline Number of washings & \multicolumn{2}{l}{ Surface resistance, $R_{\mathrm{s}}(\Omega)$} \\
\cline { 2 - 3 } & \multicolumn{1}{l}{ Fabric } & \\
\cline { 2 - 3 } & CO10AgNWs & CV15AgNWs \\
\hline 0 & $20 \pm 5$ & $46 \pm 3$ \\
1 & $23 \pm 5$ & $2.14 \times 10^{5} \pm 0.3 \times 10^{5}$ \\
2 & $22 \pm 3$ & $1.4 \times 10^{11} \pm 0.2 \times 10^{11}$ \\
25 & $55 \pm 3$ & - \\
50 & $195 \pm 6$ & - \\
\hline
\end{tabular}

Table 3 TG/DTG data of PVP, AgNW colloid, unmodified and modified cotton and viscose fabrics

\begin{tabular}{|c|c|c|c|c|c|c|c|}
\hline Sample & $T_{\text {Onset }}\left({ }^{\circ} \mathrm{C}\right)$ & $T_{\text {End }}\left({ }^{\circ} \mathrm{C}\right)$ & $T_{\text {Peak1 }}\left({ }^{\circ} \mathrm{C}\right)$ & $T_{\text {Onset }}\left({ }^{\circ} \mathrm{C}\right)$ & $T_{\text {End }}\left({ }^{\circ} \mathrm{C}\right)$ & $\mathrm{T}_{\text {Peak2 }}\left({ }^{\circ} \mathrm{C}\right)$ & Weight loss at $600{ }^{\circ} \mathrm{C}(\%)$ \\
\hline PVP & & & & 414.3 & 453.5 & 434.0 & 93.75 \\
\hline AgNWs colloid & & & & 392.4 & 455.4 & 430.6 & 55.91 \\
\hline \multicolumn{8}{|l|}{ Cotton } \\
\hline $\mathrm{CO}$ & 340.3 & 387.3 & 365.5 & & & & 87.47 \\
\hline CO1AgNWs & 335.5 & 391.6 & 367.0 & & & & 86.32 \\
\hline CO10AgNWs & 324.4 & 395.8 & 370.0 & 414.6 & 465.5 & 432.0 & 73.70 \\
\hline CO10AgNWs/25 & 333.6 & 392.4 & 369.0 & & & & 76.85 \\
\hline CO10AgNWs/50 & 333.9 & 389.8 & 363.9 & & & & 76.72 \\
\hline \multicolumn{8}{|l|}{ Viscose } \\
\hline $\mathrm{CV}$ & 292.6 & 367.8 & 343.3 & & & & 84.49 \\
\hline CV1AgNWs & 300.1 & 367.3 & 343.9 & & & & 82.60 \\
\hline CV10AgNWs & 285.4 & 366.7 & 345.0 & & & & 74.52 \\
\hline CV15AgNWs & 304.0 & 366.3 & 341.5 & 385.3 & 470.3 & 419.3 & 70.37 \\
\hline CV15AgNWs/1 & 300.8 & 367.7 & 342.0 & & & & 78.78 \\
\hline CV15AgNWs/2 & 307.1 & 363.9 & 341.4 & & & & 80.02 \\
\hline
\end{tabular}

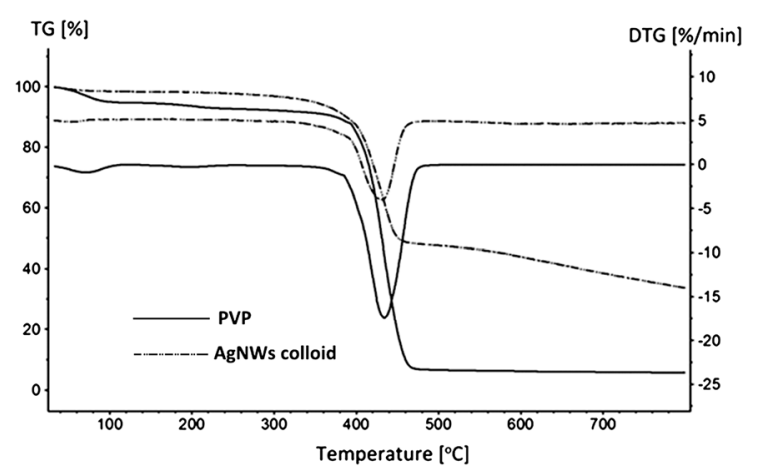

Fig. 12 TG/DTG thermogram of PVP and AgNW colloid

depending on the dipping number is preserved or similar, e.g., for CO1AgNW and CO10AgNW fabrics the $\mathrm{Ag}$ content is 1.15 and $13.77 \%$, respectively. From
SEM/EDS, the $\mathrm{Ag}$ content is 3.8 and $53.2 \%$ for $\mathrm{CO} 1 \mathrm{AgNW}$ and CO10AgNW fabrics, respectively.

Durability

For the best conductive CO10AgNW and CV15AgNW fabrics, abrasion resistance tests were carried out. No changes in the electrical conductivity of CO10AgNW and CV15AgNW fabrics were observed. After abrasion, the values of $R_{\mathrm{S}}$ were $23 \pm 3$ and $48 \pm 3 \Omega$ for CO10AgNWs and CV15AgNWs, respectively. Also, no changes in the AgNW layer on SEM images were observed (not shown). The AgNW coatings were durable, and abrasion did not influence the conductivity of either fabric. 

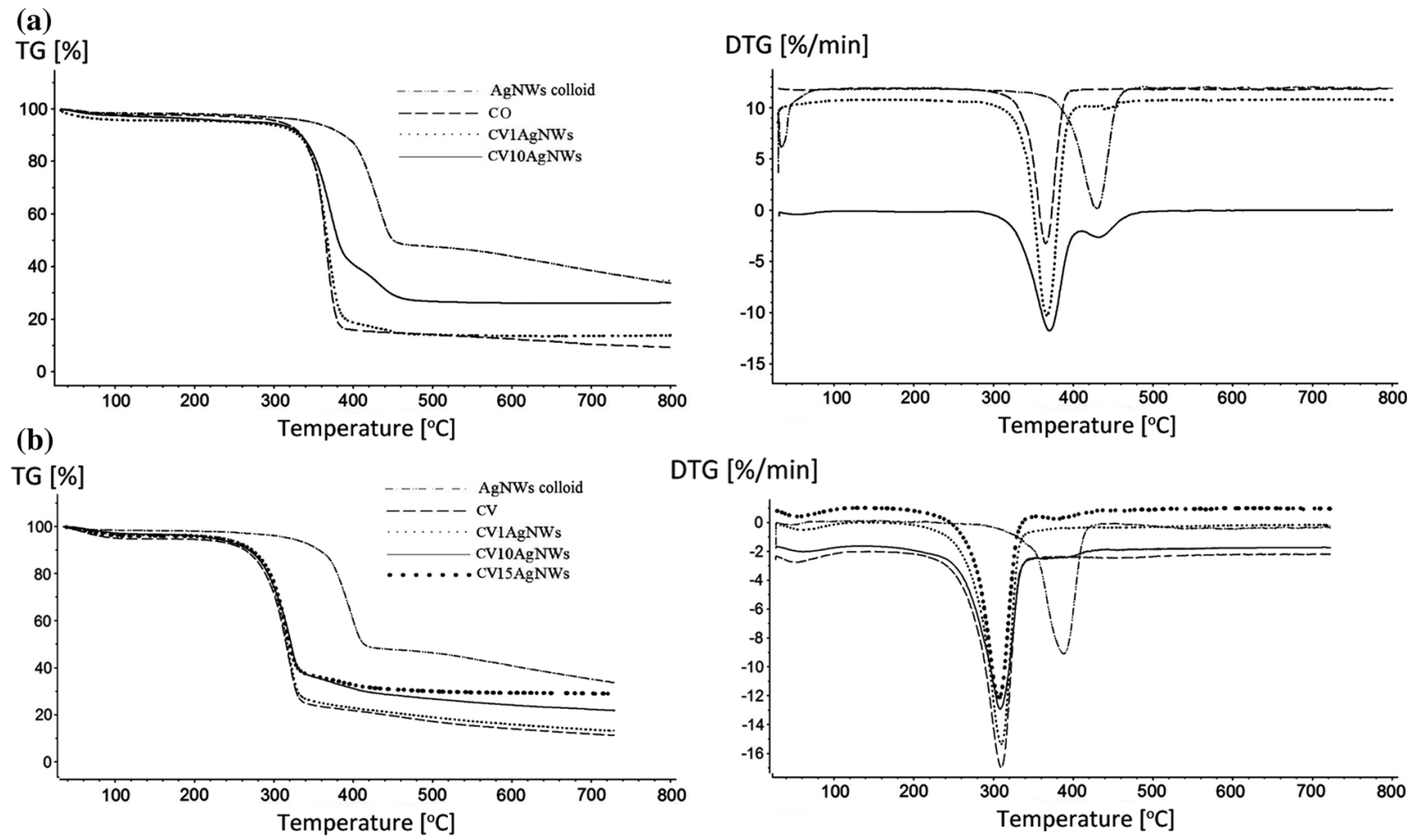

Fig. 13 TG/DTG thermogram of a AgNW colloid, unmodified and modified cotton fabrics and b AgNW colloid, unmodified and modified viscose fabrics

For the AgNW colloid synthesis, PVP was used as an AgNW stabilizer. PVP on AgNW-modified fabrics using FTIR/ATR, Raman and TG analysis was confirmed (Figs. 6, 7, 8, 9, 12, 13). The presence of this stabilizer does not interfere with the interaction between silver nanowires and the conductivity of modified fabrics, although PVP has moderate electrical conductivity $7.42 \times 10^{-8} \mathrm{~S} \mathrm{~cm}^{-1}$ (Ravi et al. 2013). The presence of PVP is necessary because the surrounding of AgNWs by a thin layer of PVP allows for the separation of each nanowire and creates a conductive network of nanowires on the fabric surface.

The impact of AgNW modification on the mechanical properties of both fabrics was evaluated. The results of the tensile strength test for modified CO10AgNW and CV15AgNW fabrics showed the growth of breaking force about $49 \%$ from $241 \mathrm{~N}$ (CO) to $472 \mathrm{~N}$ (CO10AgNWs). However, for CV15AgNW fabric the breaking force decreased from $574 \mathrm{~N}$ to $420 \mathrm{~N}$ (about 27\%). No changes of breaking elongation before and after $\mathrm{AgNW}$ modification were noted. The breaking elongation for $\mathrm{CO}$ and $\mathrm{CO} 10 \mathrm{AgNW}$ fabrics is 10.2 and $9.90 \%$, respectively, and for $\mathrm{CV}$ and
CV15AgNW fabric is 19.40 and $19.90 \%$, respectively. Similar results of lower strength viscose fabric after modifications (among others with $\mathrm{TiO}_{2}$ ) were observed in our previous work (Giesz et al. 2016).

The differences in the results of AgNW application, durability of the modification effect and changes of tensile strength for two cellulose fabrics are related to the variety of their morphological and topographical structures, discussed by Giesz et al. (2016).

\section{Antibacterial effect}

The Ag content for CO10AgNW and CV15AgNW fabrics is similar, but other properties such as the tensile strength are worse for CV15AgNWs; therefore, the antibacterial properties were evaluated for CO10AgNW fabric against S. aureus and K. pneumoniae bacteria. No reduction in either bacteria colony was found in the case of unmodified $\mathrm{CO}$ fabric. The percentage reduction of $S$. aureus and $K$. pneumoniae seeded on CO10AgNW fabric was 94.7 and $97.7 \%$, respectively, and we can conclude that such modification of $\mathrm{CO}$ fabric is effective against gram-positive and -negative bacteria. The good antibacterial effect 
could be attributed to a high degree of surface coverage with AgNWs.

\section{Conclusions}

Multifunctional cotton and viscose fabrics modified with silver nanowires (AgNWs) by the dipping-drying method were obtained. AgNW loading on the fabric surfaces gives them conductive properties, which depend on the amount of AgNWs and connections between nanowires. To achieve good electrical conductivity, the dipping process in AgNW colloid was repeated 10 times and 15 times for cotton (CO10AgNWs) and viscose (CV15AgNWs) fabrics, respectively. More effective modification of cotton compared to viscose fabric was observed. The average surface resistance of 20 and $46 \Omega$ was $\mathrm{Ag} 53.2 \mathrm{wt} \%$ for CO10AgNW and $\mathrm{Ag} 52.3 \mathrm{wt} \%$ for CV15AgNWs, respectively. The electrical conductivity of CO10AgNWs dropped slightly after 50 washes $\left(R_{\mathrm{S}}\right.$ increased from 20 to $195 \Omega$ ), while for CV15AgNWs after two washes, the fabric beceme nonconductive $\left(R_{\mathrm{S}}\right.$ increased from 46 to $1.4 \times 10^{11} \Omega$ ). The $\mathrm{AgNW}$ layer on the fabric surface is resistant to abrasion. The tensile strength after modifications with AgNW colloid increased about $49 \%$ for CO10AgNW fabric and decreased about $27 \%$ for CV15AgNWs. The AgNWmodified cotton fabric surface caused a significant antibacterial effect against gram-positive (S. aureus) and -negative bacteria ( $K$. pneumoniae). The effectiveness of the modification depends on the type of cellulose textile material used. The presented modification method with AgNWs is more suitable for cotton than for viscose fabric. Cotton fabric modified with AgNWs preserves its mechanical properties and retains its conductivity even after many washings. The developed electroconductive and antimicrobial cotton fabric can be used in further studies concerning E-textiles.

Acknowledgments The study was carried out within the internal project BZT 0149/2016 on the apparatus purchased in projects POIG.01.03.01-00-004/08 Functional nano- and micro textile materials-NANOMITEX, co-financed by the European Union with the financial resources of the European Regional Development Fund and the National Centre for Research and Development and WND-RPLD.03.01.00-001/09, co-financed by the European Union with the financial resources of the European Regional Development Fund and the Ministry of Culture and National Heritage. The authors would like to thank
Ms. Dorota Puchowicz, Ms. Stanisława Wróbel and Ms. Magdalena Kiwała for their technical contributions to the experimental work.

Open Access This article is distributed under the terms of the Creative Commons Attribution 4.0 International License (http:// creativecommons.org/licenses/by/4.0/), which permits unrestricted use, distribution, and reproduction in any medium, provided you give appropriate credit to the original author(s) and the source, provide a link to the Creative Commons license, and indicate if changes were made.

\section{References}

Agarwal S, Tyagi T, Gupta VK, Golbaz F, Golikand AN, Moradi O (2016) Synthesis and characteristics of polyaniline/zirconium oxide conductive nanocomposite for dye adsorption application. J Mol Liq 218:494-498

Bahadur I, Momin MIK, Koorbanally NA, Sattari M, Ebenso EE, Katata-Seru LM, Singh S, Ramjugernath D (2016) Interactions of polyvinylpyrrolidone with imisazolium based ionic liquids: spectroscopic and density functional theory studies. J Mol Liq 213:13-16

Capineri L (2014) Resistive sensors with smart textiles for wearable technology: from fabrication processes to integration with electronics. Proc Eng 87:724-727

Cieślak M, Wróbel S, Kamińska I, Lao M (2009) Functional upholstery materials for protection against electrostatic risk. Fibre Text East Eur 17:52-58

Cui HW, Suganuma K, Uchida H (2015) Highly stretchable, electrically conductive textiles fabricated from silver nanowires and cupro fabrics using a simple dipping-drying method. Nano Res 8:1604-1614

Dias T (Ed) (2015) Electronic textiles: Smart fabrics and wearable technology. Woodhead Publishing, Elsevier, eBook ISBN 9780081002230

Dong H, Wu Z, Lu F, Gao Y, El-Shafei A, Jiao B, Ning S, Hou X (2014) Optics-electrics highways: plasmonic silver nanowires@ $\mathrm{TiO}_{2}$ core-shell nanocomposites for enhanced dye-sensitized solar cells performance. Nano Energy 10:181-191

Eom H, Jung JY, Shin Y, Kim S, Choi JH, Lee E, Jeong IH, Park I (2014) Strong localized surface plasmon resonance effects of $\mathrm{Ag} / \mathrm{TiO}_{2}$ core-shell nanowire arrays in $\mathrm{UV}$ and visible light for photocatalytic activity. Nanoscale 6:226-234

Foksowicz-Flaczyk J, Walentowska J, Przybylak M, Maciejewski H (2016) Multifunctional durable properties of textile materials modified by biocidal agents in the solgel process. Surf Coat Technol. doi:10.1016/j.surfcoat. 2016.06.062

Giesz P, Celichowski G, Puchowicz D, Kamińska I, Grobelny J, Batory D, Cieślak M (2016) Microwave-assisted $\mathrm{TiO}_{2}$ : anatase formation on cotton and viscose fabric surfaces. Cellulose 23:2143-2159

Gowri S, Almeida L, Amorim T, Carneiro N, Souto AP, Esteves MF (2010) Polymer nanocomposites for multifunctional finishing of textiles—a review. Text Res J 80:1290-1306 
Hong HK, Park CK, Gong MS (2010) Preparation of Ag/PVP nanocomposites as a solid precursor for silver nanocolloids solution. Bull Korean Chem Soc 31:1252-1256

Jiang ZJ, Liu CY, Sun LW (2005) Catalytic properties of silver nanoparticles supported on silica spheres. J Phys Chem B 109:1730-1735

Johnsen GK, Knaapila M, Martinsen QG, Helgesen G (2012) Conductivity enhancement of silver filled polymer composites through electric field alignment. Compos Sci Technol 72:1841-1847

Kim BC, Innis PC, Wallace GG, Low CTJ, Walsh FC, Cho WJ, $\mathrm{Yu}$ KH (2013) Electrically conductive coatings of nickel and polypyrrole/poly(2-methoxyaniline-5-sulfonic acid) onnylonLycra $^{\circledR}$ textiles. Prog Org Coat 76(2013):12961301

Kowalczyk D, Brzeziński S, Makowski T, Fortuniak W (2015) Conductive hydrophobic hybrid textiles modified with carbon nanotubes. Appl Surf Sci 357:1007-1014

Makowski T, Kowalczyk D, Fortuniak W, Brzeziński S, Kregiel D (2015) Electrochemical deposition of silver nanoparticle and polymerization of pyrrole on fabrics via conducting multiwall carbon nanotubes. Cellulose 22:3063-3075

Martina I, Wiesinger R, Jembrich-Simburger D, Schreiner M (2012) Micro-raman characterisation of silver corrosion products: instrument set au and reference database, in e-preservation science. Morana rtd. ISSN 1581-9820, e-PS, 9, 1-8

Mohd RJ, Aznan NAK, Yee ST, Ho IH, Ooi SW, Singho ND, Aplop F (2014) Synthesis and growth mechanism of silver nanowires through different mediated agents $\left(\mathrm{CuCl}_{2}\right.$ and $\mathrm{NaCl}$ ) polyol process. J Nanomater 2014:105454. doi:10. $1155 / 2014 / 105454$

Nasirizadeh N, Dehghani M, Yazdanshenas ME (2015) Preparation of hydrophobic and conductive cotton fabrics using multi-wall carbon nanotubes by the sol-gel method. J Sol Gel Sci Technol 73:14-21

Nateghi MR, Shateri-Khalilabad M (2015) Silver nanowirefunctionalized cotton fabric. Carbohydr Polym 117:160168

Nateghi MR, Dehghan S, Shateri-Khalilabad M (2013) A facilile route for fabrication of conductive hydrophobic textile materials using N-octyl/N-perfluorohexyl substituted polypyrrole. Int $\mathrm{J}$ Polym Mater Polym Biomater 62:648-652

Rattfalt L, Linden M, Hult P, Berglin L, Ask P (2007) Electrical characteristics of conductive yarns and textile electrodes for medical applications. Med Biol Eng Comput 45:1251-1257

Ravi M, Bhavani S, Kiran Kumar K, Narasimaha Rao VVR (2013) Investigations on electrical properties of PVP:KIO polymer electrolyte films. Solid State Sci 18:85-93

Selvam S, Sundrarajan M (2012) Functionalization of cotton fabric with $\mathrm{PVP} / \mathrm{ZnO}$ nanoparticles for improved reactive dyeability and antibacterial activity. Carbohydr Polym 87:1419-1424

Shateri-Khalilabad M, Yazdanshenas ME (2013) Fabricating electroconductive cotton textiles using graphene. Carbohydr Polym 96:190-195
Shen W, Dong Y, Cui G, Li B (2016) Optimized preparation of electrically conductive cotton fabric by an industrialized exhaustion dyeing with reduced graphene oxide. Cellulose 23:3291-3300

Shobin LR, Manivannan S (2014) One pot rapid synthesis of silver nanowires using $\mathrm{NaCl}$ assisted glycerol mediated polyol process. Electron Mater Lett 10:1027-1031

Stempien Z, Rybicki E, Rybicki T, Lesnikowski J (2016) Inkjetprinting deposition of silver electro-conductive layers on textile substrates at low sintering temperature by using an aqueous silver ions-containing ink for textronic applications. Sens Actuators B Chem 224:714-725

Stoppa M, Chiolerio A (2014) Wearable electronic and smart textiles: a critical review. Sensor 14:11957-11992

Sun Y, Gates B, Mayers B, Xia Y (2002) Crystalline silver nanowires by soft solution processing. Nano Lett 16:5-168

Sundarshan Reddy K, Prabhakar MN, Nagommaheswara Reddy V, Sathyamaiah G, Maruthi Y, Subha MCS, Chowdoi Rao K (2012) Miscibility studies of hydroxypropyl cellulose/ poly(vinylpyrrolidone) in dilute solutions and solid state. J Appl Polym Sci 125:2289-2296

Tang Y, He Z, Mosseler JA, Ni Y (2014) Production of highly electro-conductive cellulosic paper via surface coating of carbon nanotube/graphene oxide nanocomposites using nanocrystalline cellulose as a binder. Cellulose 21:4569-4581

Tao Y, Wang L, Wang B, Yang Z, Tai Y (2013) High-reproducibility, flexible conductive patterns fabricated with silver nanowire by drop or fit-to-flow method. Nanoscale Res Lett 8:147-151

Tarabella G, Villani M, Calestani D, Mosca R, Iannotta S, Zappettini A, Coppede N (2012) A single cotton fiber organic electrochemical transistor for liquid electrolyte saline sensing. J Mater Chem 22:23830-23834

Usma C, Kouzani AC, Chua JJC, Arogbonlo A, Adams S, Gibson I (2015) Fabrication of force sensor circuits on wearable conductive textiles. Proc Technol 20:263-269

Wang CB, Deo G, Wachs IE (1999) Interaction of polycrystalline silver with oxygen, water, carbon dioxide, ethylene and methanol: in situ raman and catalytic studies. J Phys Chem B 103:5645-5656

Wang Z, Liu J, Chen X, Wan J, Qian Y (2005) A simple hydrothermal route to large-scale synthesis of uniform silver nanowires. Chem Eur J 11:160-163

Xia Y, Sun Y (2002) Large-scale synthesis of uniform silver nanowires through a soft, self-seeding, polyol process. Adv Mater 14:833-837

Zhao YP, Cai ZS, Fu XL, Song BZ, Zhu HY (2013) Electrochemical deposition and characterization of copper crystals on polyaniline/poly (ethylene terephthalate) conductive textiles. Synth Met 175:1-8

Zhou Y, Ding X, Zhang J, Duan Y, Hu J, Yang X (2014) Fabrication of conductive fabric as textile electrode for ECG monitoring. Fiber Polym 15:2260-2264 